\title{
Calycosin Induces Gastric Cancer Cell Apoptosis via the ROS-Mediated MAPK/STAT3/NF-KB Pathway
}

\author{
Yu Zhang ${ }^{1} *$ \\ Jian-Qiang Zhang ${ }^{2,3, *}$ \\ Tong Zhang' \\ Hui Xue' \\ Wen-Bo Zuo' \\ Yan-Nan Li iD ' \\ Yue Zhao' \\ Geng Sun' \\ Zhong-Ren Fu' \\ Qing Zhang' \\ Xue Zhao' \\ Yue Teng' \\ An-Qi Wang' \\ Jia-Zhu Li' \\ Ying Wang ${ }^{4,5}$ \\ Cheng-Hao Jin ${ }^{1,4,5}$
}

'Department of Biochemistry and Molecular Biology, College of Life Science \& Technology, Heilongilan Bayi Agricultural University, Daqing, People's Republic of China; ${ }^{2}$ Department of Food Science and Technology, College of Food Science, Northeast Agricultural University, Harbin, People's Republic of China; ${ }^{3}$ Heilongiang Heyi Dairy Technology Co. Ltd., Daqing, People's Republic of China; ${ }^{4}$ Department of Food Science and Engineering, College of Food Science \& Technology, Heilongiiang Bayi Agricultura University, Daqing, People's Republic of China;

${ }^{5}$ National Coarse Cereals Engineering Research

Center, Daqing, People's Republic of China

*These authors contributed equally to this work

Correspondence: Cheng-Hao Jin

Department of Biochemistry and Molecular Biology, College of Life Science \&

Technology, Heilongjiang Bayi Agricultural

University, 5 Xinfa Street, Daqing,

Heilongjiang, I63319, People's Republic of

China

Email jinchenghao3727@qq.com

Ying Wang

Department of Food Science and Engineering, College of Food Science \&

Technology, Heilongjiang Bayi Agricultural

University, 5 Xinfa Street, Daqing,

Heilongjiang, 163319, People's Republic of

China

Email wychenI56@I63.com
This article was published in the following Dove Press journal: OncoTargets and Therapy

Background: Calycosin, an active compound in plants, can promote the apoptosis of various cancer cells; however, the mechanism by which it regulates reactive oxygen species (ROS) in gastric cancer (GC) cells remains unclear.

Purpose: In this study, we investigated the effects of calycosin on apoptosis, the cell cycle, and migration in GC cells under ROS regulation.

Results: The results of the Cell Counting Kit- 8 assay suggested that calycosin had significant cytotoxic effects on 12 gastric cancer cells, but no significant cytotoxic effects on normal cells. Hoechst 33342/propidium iodide (PI) double staining and flow cytometry showed that calycosin had clear pro-apoptotic effects on AGS cells. Western blotting revealed that the expression of cytochrome $\mathrm{C}$ and pro-apoptotic proteins B-cell lymphoma 2 (Bcl-2)-associated agonist of cell death (Bad), cleaved (cle)-caspase-3, and cle-poly (ADPribose) polymerase gradually increased, and the expression of anti-apoptotic protein Bcl-2 gradually decreased. Calycosin also decreased the expression of extracellular signalregulated kinase, nuclear factor kappa $\mathrm{B}(\mathrm{NF}-\kappa \mathrm{B})$, and signal transducer and activator of transcription 3 (STAT3), and increased the phosphorylation levels of p38, c-Jun N-terminal kinase, and inhibitor of NF- $\kappa$ B. In addition, calycosin markedly increased ROS accumulation, and pretreatment with active oxygen scavenger n-acetyl-1-cysteine (NAC) clearly inhibited apoptosis. Calycosin downregulated the cell cycle proteins cyclin-dependent kinase 2 (CDK2), CDK4, CDK6, cyclin D1, and cyclin E; upregulated p21 and p27; and arrested cells in the G0/G1 phase. Similarly, calycosin also downregulated Snail family transcriptional repressor 1, E-cadherin, and $\beta$-catenin and inhibited cell migration. However, pretreatment with NAC inhibited the calycosin-induced effects of cycle arrest and migration.

Conclusion: In summary, calycosin induces apoptosis via ROS-mediated MAPK/STAT3/ $\mathrm{NF}-\kappa \mathrm{B}$ pathways, thereby exerting its anti-carcinogenic functions in GC cells.

Keywords: calycosin, human gastric cancer, apoptosis, cell cycle, cell migration, reactive oxygen species

\section{Introduction}

With the irregular diet and life of modern people, the incidence of gastric cancer (GC) is gradually increasing. According to the prediction of Joinpoint software, the total number of GC cases will increase with the aging of China's population, which is a serious threat to human health and life. ${ }^{1,2}$ Although significant progress has been made in GC treatments over the past few decades, the survival rate of GC patients remains poor. ${ }^{3,4}$ Several first-line chemotherapy drugs inevitably lead to resistance, strong adverse reactions, and toxicity that damages the normal cell 
morphology, resulting in low survival rates. ${ }^{5}$ The above factors have greatly limited advancements in chemotherapy. To overcome this issue with chemotherapy drugs and improve the survival rate, highly efficient Chinese herbs with low toxicity during the treatment process have recently garnered increasing attention.

In the process of aerobic cell metabolism, if oxygen is not completely reduced to water, it generates oxygen free radicals and non-radical oxygen, both of which are known as reactive oxygen species (ROS) ${ }^{6,7}$ Excessive ROS are generated in mitochondria from tumor cells, which can cause damage to the bacterial biofilm on the cell and simultaneously suppress cancer cell proliferation, and cause apoptosis, cell cycle arrest, and migration by regulating the mitogen-activated protein kinase (MAPK), signal transducer and activator of STAT3, and NF- $\kappa B$ signaling pathways. ${ }^{8-10}$ These processes are involved in oxidative stress. Cytochrome $\mathrm{C}$ and the activation of caspase-3 can cleave the PARP substrates, including the pro-apoptotic protein B-cell lymphoma 2 (Bcl-2)-associated agonist of cell death (Bad) and antiapoptotic protein B-cell lymphoma 2 (Bcl-2), all of which promote activation of cell apoptotic pathways. ${ }^{11,12}$

Research on the treatment of cancer by traditional Chinese medicine (TCM) extracts has led to great progress in understanding the mechanism of action and mode of administration of a single Chinese medicine. ${ }^{13-15}$ Calycosin is a fat-soluble component in the dried root of Astragalus membranaceus, which are organic compounds widely found in nature. Calycosin exerts various antitumor activities in vitro and in vivo, ${ }^{16-18}$ but its mechanism of action in human GC cells is not clear.

In this study, we evaluated the effects of calycosin on apoptosis, the cell cycle, and migration of GC cells under ROS regulation. In addition, we also determined the roles of MAPK/STAT3/NF- $\kappa B$ pathways in these processes.

\section{Materials and Methods}

\section{Cell Lines and Cell Culture}

Twelve types of GC cells (AGS, KATO-3, MKN-28, MKN-45, NCI-N87, SNU-5, SNU-216, SNU-484, SNU668, YCC-1, YCC-6, and YCC-16) and normal human lung cells IMR-90 were purchased from American Type Culture Collection (Manassas, VA, USA), and three normal cell lines (GES-1, L-02, and 293T) were purchased from Saiqi Biotech Co., Ltd (Shanghai, China). AGS, KATO-3, MKN-28, MKN-45, SNU-5, SNU-216, SNU-
484, SNU-668, IMR-90, and L-02 cells were maintained in RPMI 1640 medium (Gibco, Waltham, MA, USA). NCI-N87, YCC-1, YCC-6, YCC-16, GES-1, and 293T cells were grown in Dulbecco's Modified Eagle Medium (Gibco) supplemented with $10 \%$ fetal bovine serum (Gibco), $100 \mathrm{U} / \mathrm{mL}$ penicillin (Gibco), and $100 \mu \mathrm{g} / \mathrm{mL}$ streptomycin (Gibco). All cells were cultured in a humidified atmosphere of $5 \% \mathrm{CO}_{2}$ incubator (Sanyo, Osaka, Japan) at $37^{\circ} \mathrm{C}$, and the number of cells maintained at $80 \%$.

\section{Cell Counting Kit-8 Assay}

The cytotoxic effects of calycosin on $12 \mathrm{GC}$ cells and 4 normal cells were assessed using the Cell Counting Kit-8 (CCK-8) assay (Solabio, Beijing, China). In brief, 16 cells in the logarithmic growth phase were inoculated into a 96well plate $\left(1 \times 10^{4}\right.$ cells/well $)$ overnight. Then the cells in each well were treated with calycosin (Chengdu, China) and cisplatin (Princeton, NJ, USA), and $10 \mu \mathrm{L} \mathrm{CCK-8}$ (Solarbio, Beijing, China) solution, and the cell viability was measured by the enzyme-linked immunosorbent assay (BioTek Instruments, Inc., Winooski, VT, USA).

\section{Cell Apoptosis Analysis}

AGS cells were seeded in a 6-well plate and treated with $47 \mu \mathrm{M}$ calycosin for $24 \mathrm{~h}$. Then the cells were detected using the Hoechst 33342/PI Dual Staining Kit (Solarbio), Annexin V Apoptosis Detection Kit (Solarbio), and Mitochondrial Membrane Potential Assay Kit (Solarbio). According to the manufacturer's instructions, the cells were stained with Hoechst 33342 and PI for 15 min. The cell morphology was observed using the EVOS FL Auto Cell Imaging System (Thermo Fisher Scientific, Waltham, MA, USA). Furthermore, the AGS cells were cultured in $95 \mu \mathrm{L}$ Annexin V Binding Buffer, followed by the addition of Annexin V-FITC and PI, after which the apoptotic cells were analyzed by flow cytometry (Beckman Coulter, Inc., Brea, CA, USA). In addition, the AGS cells were incubated with $1 \mathrm{~mL} \mathrm{JC}-1$ staining solution at $37^{\circ} \mathrm{C}$ for $20 \mathrm{~min}$, and changes in mitochondrial membrane potential were analyzed by flow cytometry.

\section{Measurement of Cellular ROS Levels}

AGS cells were treated with $47 \mu \mathrm{M}$ calycosin for different time points $(3,6,12$, and $24 \mathrm{~h})$ in the logarithmic growth phase. The cells were centrifuged for $5 \mathrm{~min}$ at $6000 \times \mathrm{g}$, followed by washing with phosphate-buffered saline (PBS). The cells were stained with $10 \mu \mathrm{mol} / \mathrm{L}$ DCFH-DA 
probe (Beyotime Institute Biotechnology, Shanghai, China) in a $37^{\circ} \mathrm{C}$ constant temperature water bath (Senxin, Jiangsu, China) for $30 \mathrm{~min}$. After the cells were re-suspended with PBS, the level of intracellular ROS was measured using a flow cytometer. AGS cells were pretreated by adding n-acetyl-1-cysteine (NAC) (Beyotime Institute Biotechnology), and apoptotic cells were analyzed by flow cytometry.

\section{Analysis of Cell Cycle Arrest}

AGS cells in the logarithmic growth phase were exposed to calycosin for different time points $(3,6,12$, and $24 \mathrm{~h})$, and fixed in $70 \% \mathrm{EtOH}$ overnight at $4{ }^{\circ} \mathrm{C}$. Then AGS cells were stained using the DNA Content Quantitation Assay Kit (Solarbio), followed by incubation in a $37^{\circ} \mathrm{C}$ constant temperature water bath for $30 \mathrm{~min}$, and the addition of 400 $\mu \mathrm{L}$ PI at $4{ }^{\circ} \mathrm{C}$ (Sanyo, Osaka, Japan) for $30 \mathrm{~min}$. The DNA content in the AGS cells treated with calycosin was measured by flow cytometry, and the cell cycle arrest was analyzed.

\section{Wound Healing Assay}

The AGS cells in logarithmic growth phase were seeded in a 6-well plate and cultured to a monolayer. Then scratches were generated by a $200 \mu \mathrm{L}$ pipette. The remaining cells were washed with PBS and cultured in serum-free RPMI 1640 medium. After $2 \mathrm{~h}, 47 \mu \mathrm{M}$ calycosin was added to the cells, and images were taken at $3,6,12$, and $24 \mathrm{~h}$.

\section{Preparation of Nuclear Extract}

Nuclear proteins were extracted using the NE-PER Nuclear and Cytoplasmic Extraction Reagent Kit (Thermo Fisher Scientific). Cells in a $3.5 \mathrm{~cm}$ dish were harvested and washed with pre-cooled PBS, followed by the addition of $60 \mu \mathrm{L}$ Cytoplasmic Extraction Reagent I for $15 \mathrm{~min}$ and incubation with Cytoplasmic Extraction Reagent II for $3 \mathrm{~min}$. The cells were centrifuged (Eppendorf, Hamburg, Germany) for $10 \mathrm{~min}$ at $13,000 \times \mathrm{g}$. The Nuclear Extraction Reagent for precipitation was shaken once every $10 \mathrm{~min}$, and the nuclear proteins were collected from the supernatant.

\section{Western Blot Analysis}

AGS cells were extracted in lysis buffer, and then centrifuged for $30 \mathrm{~min}$ at $12,000 \times \mathrm{g}$ at $4^{\circ} \mathrm{C}$. The protein sample was calculated based on the measured $\mathrm{OD}_{595}$ value and the standard curve. The protein sample was separated on $8-12 \%$ SDS-PAGE gels and then transferred onto nitrocellulose membranes (Pall Corp., Hauppauge, NY, USA). The desired target bands were cut out and blocked in 5\% skim milk (Becton Dickinson, Franklin Lakes, NJ, USA) at room temperature (RT). Then the membrane was incubated overnight with primary antibodies (Santa Cruz Biotechnology, Inc., Dallas, USA) at $4^{\circ}$ C. Then the membrane was incubated with $1 \mu \mathrm{L}$ goat antimouse IgG or goat anti-rabbit IgG secondary antibody (ZSGB Bio, Inc., Beijing, China) at RT for $2 \mathrm{~h}$. Following the incubation, Pierce ECL substrate (Thermo Fisher Scientific) was added to the membrane, and proteins were photographed using Amersham Imager 600 (GE, Fairfield, CT, USA).

\section{Statistics}

All data were analyzed by SPSS 20.0, and analyses were the average of at least three replicates. The results are presented as $\mathrm{x} \pm \mathrm{s}$. Differences in mean values between two groups were analyzed by the $t$-test, and $* p<0.05$, $* * \mathrm{p}<0.01$, and $* * * \mathrm{p}<0.001$ were considered statistically significant.

\section{Results}

\section{Cytotoxic Effects of Calycosin on Human GC Cells}

Calycosin had significant cytotoxic effects on the survival of 12 different types of GC cells in concentration- and time-dependent manners, and the toxicity was stronger than that of cisplatin (Figure 1A and C), but was lower than cisplatin in the 4 normal cell lines (Figure 1B and D). The $\mathrm{IC}_{50}$ values of cisplatin and calycosin for each cell line are shown in Table 1. AGS cells had the lowest $\mathrm{IC}_{50}$ value of $47.18 \mu \mathrm{M}$ and was most sensitive to calycosin. Therefore, AGS cells were selected for subsequent experiments.

\section{Calycosin Induces Apoptosis in AGS Cells} Hoechst 33342/PI double staining verified that calycosin significantly increased AGS cell apoptosis to $62.11 \%$ at $24 \mathrm{~h}$. The rounded edges of apoptotic cells were blurred, and the degree of apoptosis was higher than that in the cisplatin-treated group (Figure 2A). The time of AGS cells with calycosin-treated was positively correlated with the degree of apoptosis, and the number of apoptosis cells reached $64.09 \%$. It is similar with under a microscope at $24 \mathrm{~h}$ (Figure 2B). As the treatment time increased, the red-green ratio significantly 

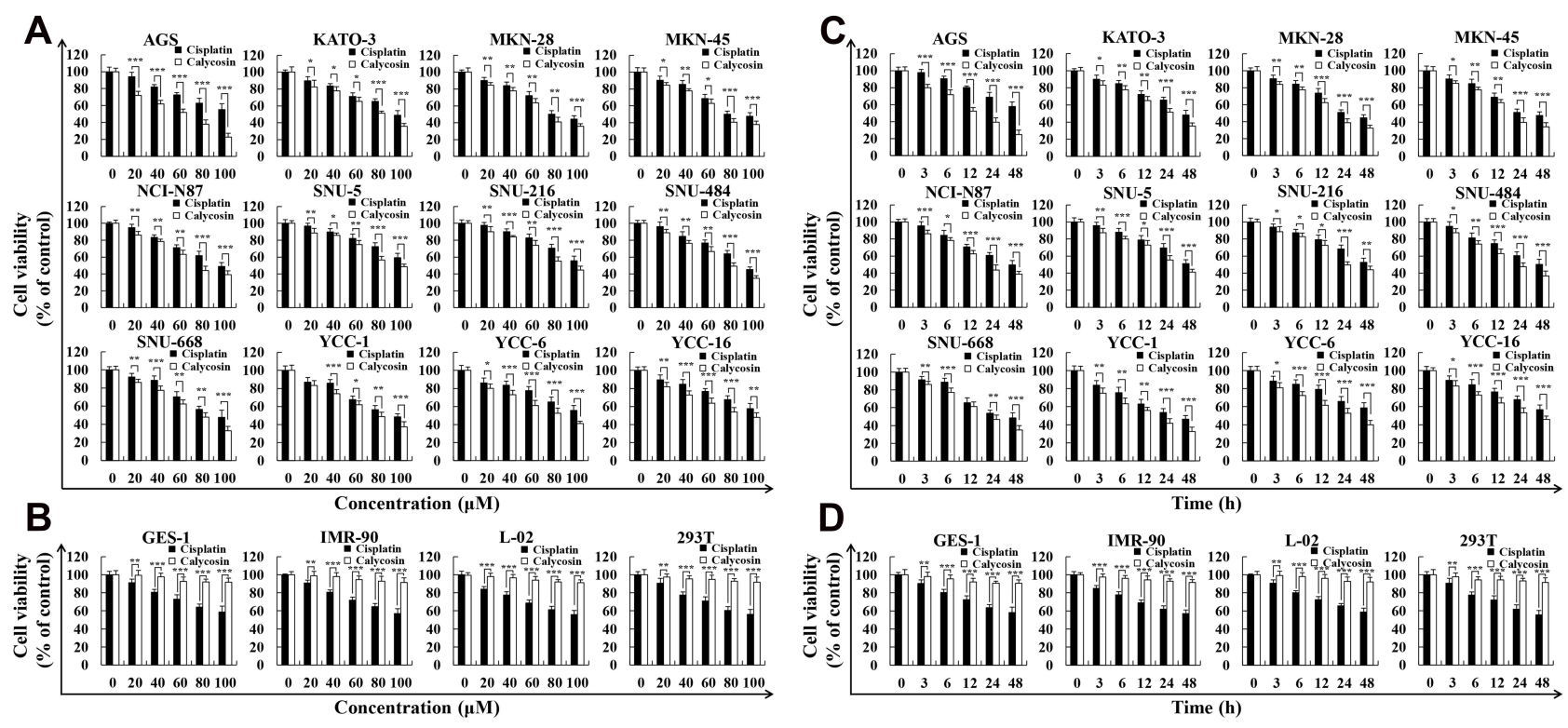

Figure I Cytotoxic effects of calycosin on GC cells. (A) Twelve human GC cell lines (AGS, KATO-3, MKN-28, MKN-45, NCI-N87, SNU-5, SNU-2I6, SNU-484, SNU-668, YCC-I, YCC-6, and YCC-16) were treated with different concentrations of calycosin and cisplatin for 24 h, and the cell cytotoxic effects were determined by the CCK-8 assay. (B) Four human normal cell lines (GES-I, IMR-90, L-02, and 293T) were treated with different concentrations of calycosin and cisplatin for 24 h, and the cell cytotoxic effects were determined by the CCK-8 assay. (C) Twelve human GC cell lines were treated with the IC 50 of calycosin and cisplatin for $0,3,6$, I2, 24, and 48 h, and the cell cytotoxic effects were determined by the CCK-8 assay. (D) Four human normal cell lines were treated with the IC 50 of calycosin and cisplatin for $0,3,6,12,24$, and $48 \mathrm{~h}$, and the cell cytotoxic effects were determined by the CCK-8 assay. Representative data from at least three independent tests. ${ }^{*} \mathrm{p}<0.05$, ${ }^{* *} \mathrm{p}<0.0 \mathrm{I}$, and ${ }^{* * *} \mathrm{p}<0.00 \mathrm{I}$.

decreased, and the mitochondrial membrane potential in the AGS cells decreased to $57.66 \%$. The decrease was most significant at $24 \mathrm{~h}$ after treatment (Figure 2C). In addition, calycosin significantly increased the protein expression levels of Bad, cle-caspase-3, cle-PARP, and cytochrome $\mathrm{C}$, while decreasing the protein expression levels of Bcl-2 (Figure 2D). Taken together, these

Table I IC 50 Value of Cisplatin and Calycosin in Twelve GC Cell Lines

\begin{tabular}{|l|c|c|c|}
\hline Number & Cell Name & Cisplatin $(\mu \mathrm{M})$ & Calycosin $(\mu \mathrm{M})$ \\
\hline 1 & AGS & $>100$ & $47.18 \pm 1.27$ \\
2 & KATO-3 & $97.79 \pm 1.41$ & $82.17 \pm 1.31$ \\
3 & MKN-28 & $80.00 \pm 1.25$ & $71.93 \pm 2.18$ \\
4 & MKN-45 & $84.78 \pm 2.39$ & $71.06 \pm 1.62$ \\
5 & NCI-N87 & $98.10 \pm 1.59$ & $74.29 \pm 2.24$ \\
6 & SNU-5 & $>100$ & $96.78 \pm 2.18$ \\
7 & SNU-216 & $>100$ & $89.49 \pm 1.56$ \\
8 & SNU-484 & $94.42 \pm 2.59$ & $78.52 \pm 2.38$ \\
9 & SNU-668 & $95.15 \pm 1.59$ & $76.34 \pm 1.13$ \\
10 & YCC-1 & $96.33 \pm 2.37$ & $77.79 \pm 2.26$ \\
11 & YCC-6 & $>100$ & $84.36 \pm 2.83$ \\
12 & YCC-16 & $>100$ & $92.24 \pm 1.66$ \\
\hline
\end{tabular}

results indicate that calycosin may induce AGS cell apoptosis.

\section{Calycosin Induces Apoptosis via the MAPK/STAT3/NF-kB Signaling Pathways in AGS Cells}

Calycosin treatment increased the expression levels of p-p38, p-JNK, and IкB- $\alpha$ and decreased the expression levels of p-ERK, p-STAT3, and NF- $\mathrm{B}$ (p65) (Figure 3A). The decreased expression of nuclear loca-

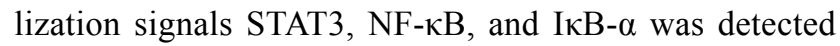
by Western blotting (Figure 3B). In addition, the FR180204 (ERK inhibitor), SB203580 (p38 inhibitor), and SP600125 (JNK inhibitor) were used to further investigate the role of calycosin in inducing apoptosis via MAPK and STAT3 signaling pathways. Inhibitors can increase the protein expression level of p-STAT3 and decrease expression of cle-caspase-3 (Figure 3C-E). Taken together, these results demonstrate that the effects of calycosin on apoptosis may be via the MAPK/STAT3/NF- $\mathrm{KB}$ signaling pathways, and MAPK may be involved in regulating the STAT3 signaling pathway in AGS cells. 
A Cisplatin

\begin{tabular}{c|c}
\hline $\mathbf{0}$ & $\mathbf{3}$ \\
\hline & \\
\hline & \\
\hline
\end{tabular}

6

12
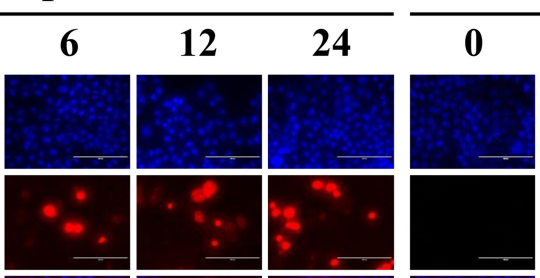

Calycosin
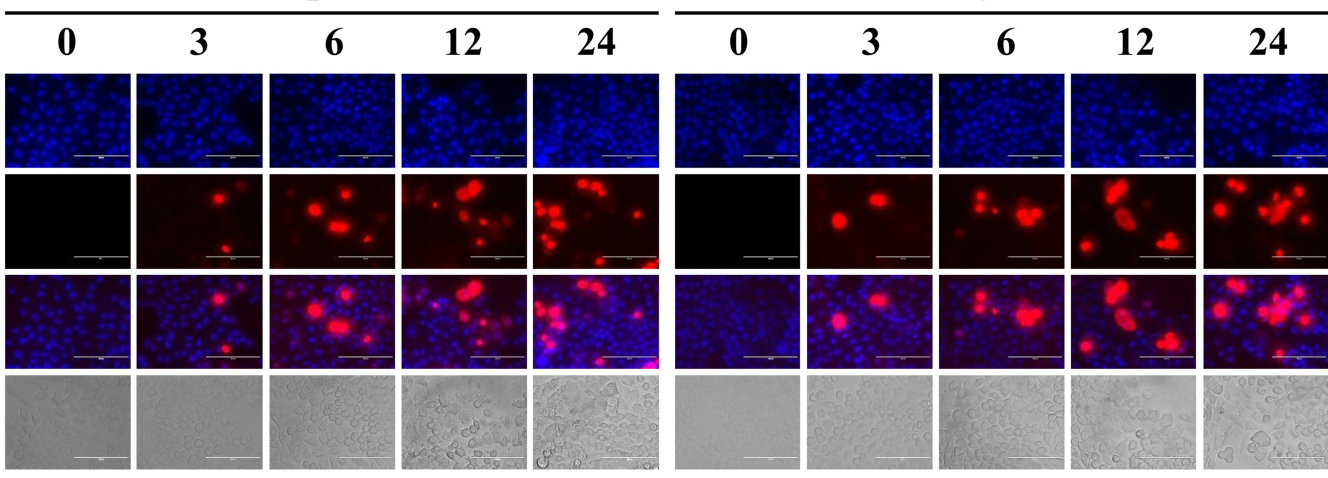

(h)

B

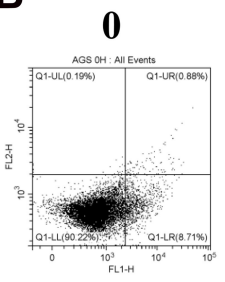

3

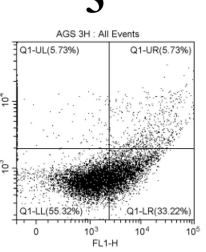

C
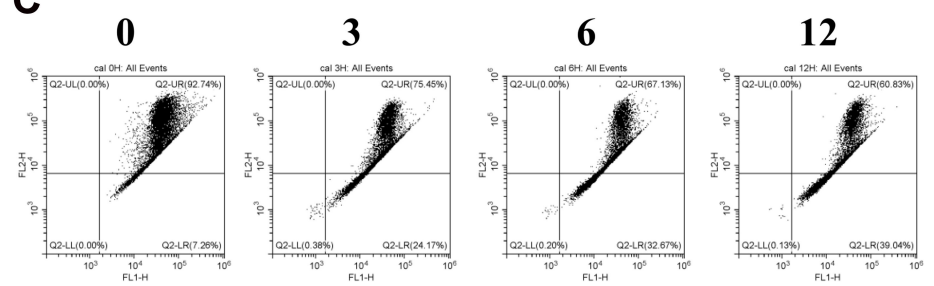

24

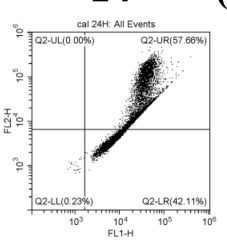

(h)

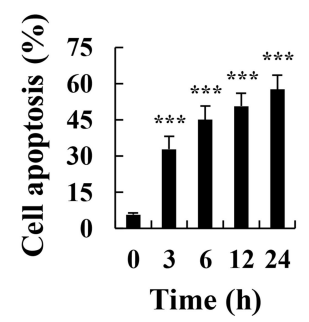

(h)

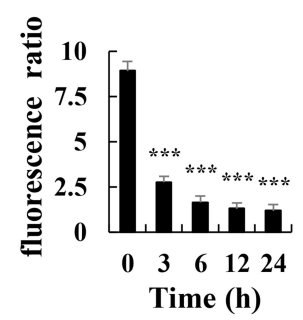

D
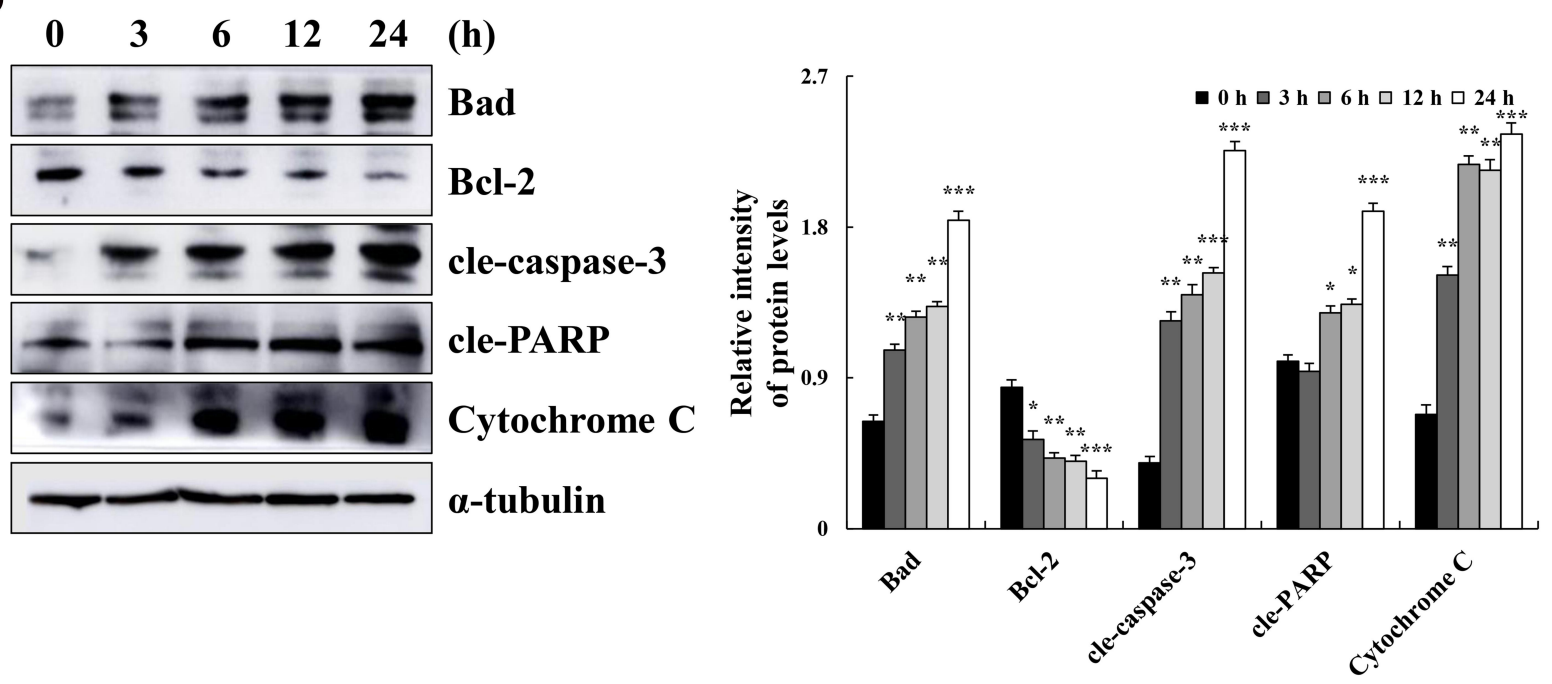

Figure 2 Calycosin induces apoptosis on AGS cells. (A) AGS cells were treated with $47 \mu \mathrm{M}$ calycosin $(0,3,6,12$, and 24 h) and stained with Hoechst $33342 / \mathrm{PI}$. Fluorescence microscopy of apoptotic AGS cells (original magnification: 400x). (B) AGS cells were stained with Annexin V-FITC/PI and analyzed by flow cytometry. (C) AGS cells were labeled with the JC-I fluorescent probe and analyzed by flow cytometry. (D) Western blot analysis of the expression levels of Bad, Bcl-2, cle-caspase-3, cle-PARP, and cytochrome $C$ in AGS cells treated with calycosin for different times $(0,3,6,12$, and $24 \mathrm{~h})$. Representative images from at least three independent tests. ${ }^{*} \mathrm{p}<0.05$, $*^{*} \mathrm{p}<$ $0.0 \mathrm{I}$, and ${ }^{* * *} \mathrm{p}<0.00 \mathrm{I}$. 


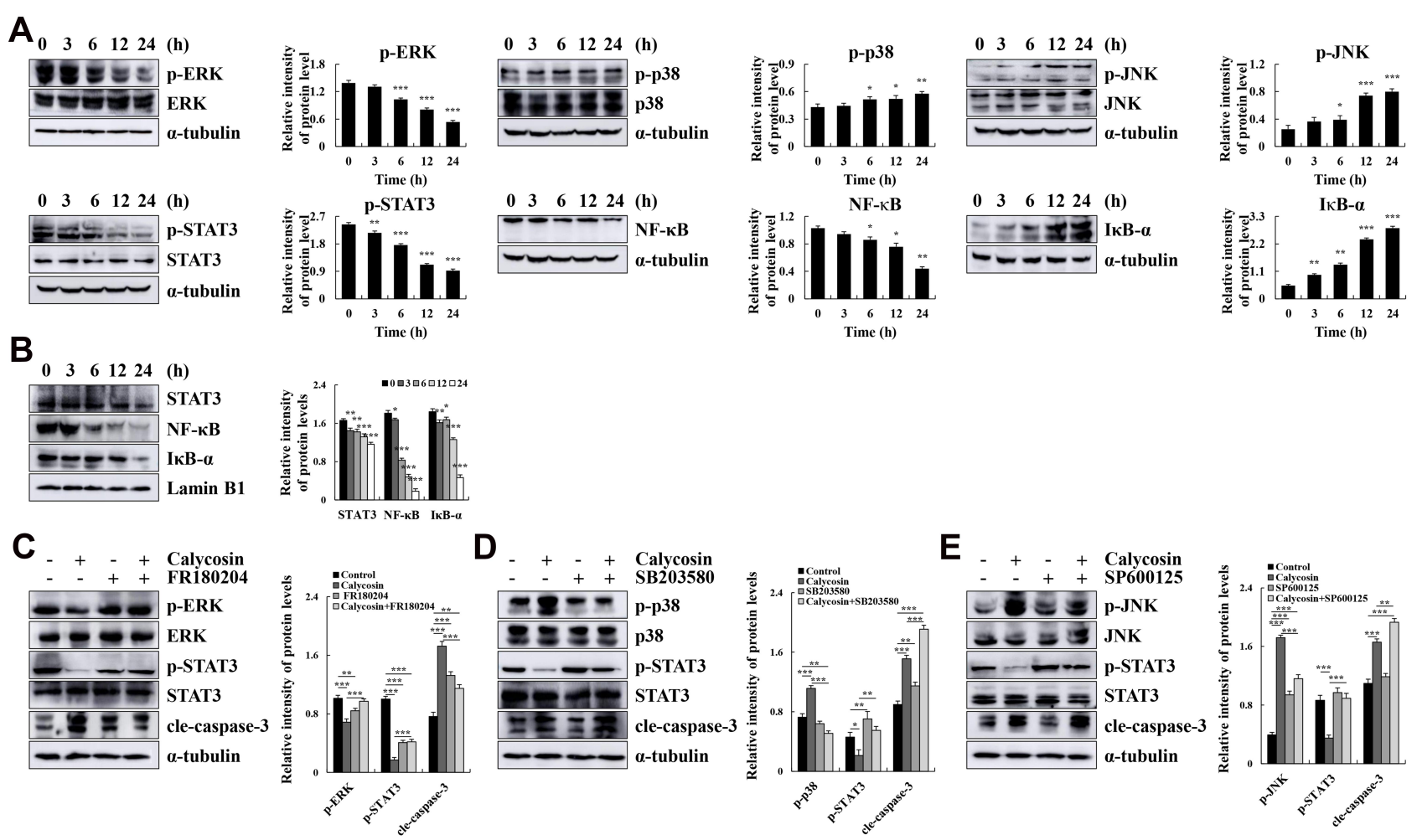

Figure 3 Calycosin affects the expression of MAPK, STAT3, and NF- $\kappa B$ pathway-related proteins in AGS cells. (A) AGS cells were treated with calycosin (0, 3, 6, I2, and 24

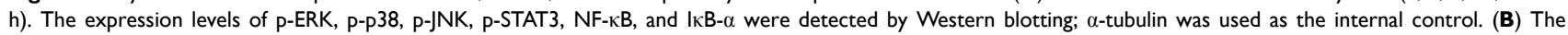
expression levels of nuclear STAT3, NF- $\kappa \mathrm{B}$, and IKB- $\alpha$ were detected by Western blotting, and Lamin BI was used as a nuclear loading control. (C) AGS cells were pretreated with FRI80204 (I2.1 $\mu \mathrm{mol} / \mathrm{L}$ ) for $30 \mathrm{~min}$, and the expression levels of p-ERK, ERK, p-STAT3, STAT3 and cle-caspase-3 were detected by Western blotting. (D) AGS cells were pretreated with SB203580 (12.1 $\mu \mathrm{mol} / \mathrm{L})$ for $30 \mathrm{~min}$, and the expression levels of p-p38, p38, p-STAT3, STAT3 and cle-caspase-3 were detected by Western blotting. (E) AGS cells were pretreated with SP600I 25 ( $12.1 \mu \mathrm{mol} / \mathrm{L})$ for $30 \mathrm{~min}$, and the expression levels of p-JNK, JNK, p-STAT3, STAT3 and cle-caspase-3 were detected by Western blotting. Representative data from at least three independent tests. ${ }^{*} p<0.05$, ${ }^{*} \mathrm{p}<0.0 \mathrm{I}$, and ${ }^{* * *} \mathrm{p}<0.00 \mathrm{I}$.

\section{Calycosin Induces AGS Cell Apoptosis Through ROS-Mediated MAPK/STAT3/ NF-кB Pathways}

Calycosin significantly increased the level of ROS to $81.52 \%$ in a time-dependent manner (Figure 4A). Compared with calycosin, apoptosis was significantly reduced to $19.37 \%$ after NAC pretreatment (Figure 4B). In addition, NAC markedly increased the expression levels of p-ERK, p-STAT3, and NF- $\mathrm{B}$ (p65), and decreased the expression levels of p-JNK, p-p38, clecaspase-3, and IкB- $\alpha$ (Figure 4C). Additionally, STAT3, $\mathrm{NF}-\kappa \mathrm{B}$, and $\mathrm{I} \kappa \mathrm{B}-\alpha$ nuclear localization signals proteins were clearly reversed after NAC treatment (Figure 4D). These results indicated that calycosin elevates the level of ROS and promotes AGS cell apoptosis through the MAPK/STAT3/NF-кB pathways.

\section{Calycosin Induces G0/GI Cell Cycle Arrest Through ROS-Mediated Signaling Pathways in AGS Cells}

Over time, calycosin increased the number of cells in the $\mathrm{G} 0 / \mathrm{G} 1$ phase to $75.24 \%$, and the proportion of cells in the $\mathrm{G} 2 / \mathrm{M}$ phase decreased to $9.84 \%$ over time (Figure 5A). The expression levels of cell cycle-related proteins were detected by Western blotting. The results showed that the expression levels of p21 and p27 were increased, and those of CDK2, CDK4, CDK6, cyclin D1, and cyclin E were decreased (Figure 5B). The number of calycosin-treated cells in the G0/G1 phase returned to $56.13 \%$, and the $\mathrm{G} 2 / \mathrm{M}$ phase returned to 25.68\% after pretreatment with NAC (Figure 5C). Relevant cell cycle-related proteins were also significantly reversed (Figure 5D). 
A

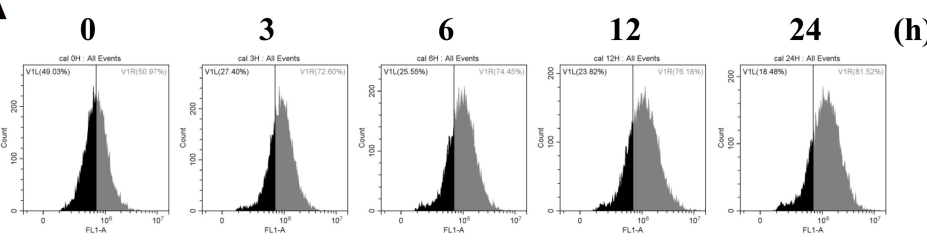

(h)

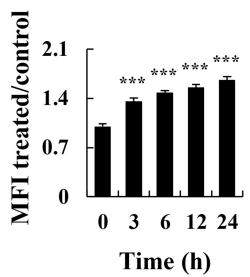

B

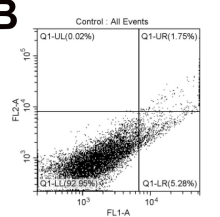

Calycosin

NAC

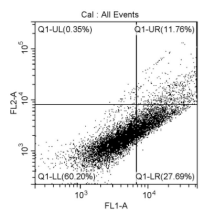

$+$

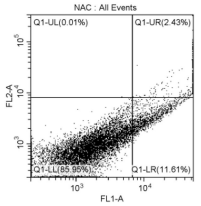

-

$+$

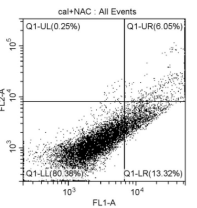

$+$

$+$

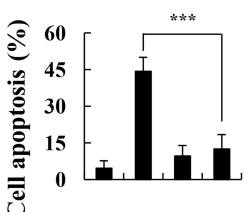

Calycosin - + +

NAC - - +

C $-+-\quad+$ Calycosin $-\quad++$ NAC

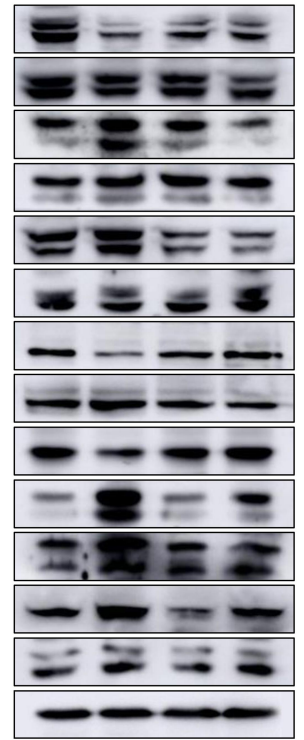
P-ERK ERK p-p38 p38 p-JNK

JNK p-STAT3

STAT3 NF- $\kappa$ B IкB- $\alpha$ cle-caspase-3 cle-PARP

Cytochrome C

D a-tubulin
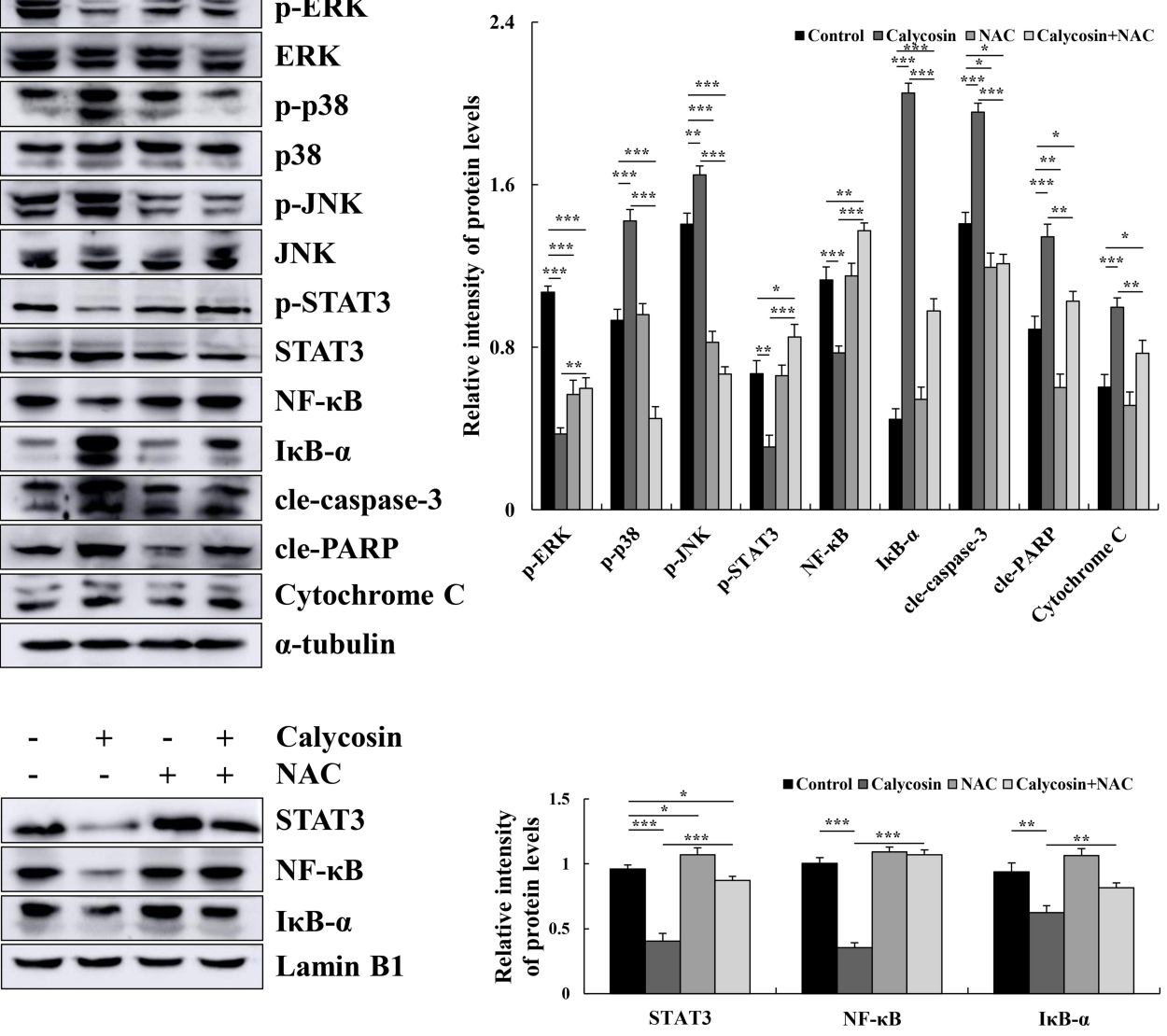

Figure 4 The effect of calycosin on intracellular ROS levels in AGS cells. (A) AGS cells were treated with calycosin (47 $\mu$ M), and ROS generation was analyzed by flow cytometry. (B) The apoptosis of AGS cells was analyzed after pretreatment with NAC by flow cytometry. (C) Western blotting was used to analyze the expression of p-ERK, p-p38, p-JNK, p-STAT3, NF- $\kappa B$, IкB- $\alpha$, cle-caspase-3, cle-PARP, and cytochrome C protein; $\alpha$-tubulin was used as the internal control. (D) Nuclear STAT3, NF- $\kappa B$, and IKB- $\alpha$ expression levels were determined by Western blotting; Lamin BI was used as a nuclear loading control. Representative data from at least three independent tests. * $\mathrm{P}$ $<0.05, * * \mathrm{p}<0.01$, and ${ }^{* * *} \mathrm{p}<0.001$. 
A

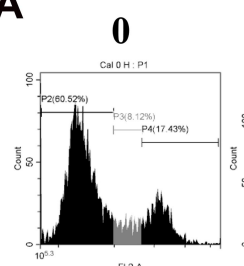

3

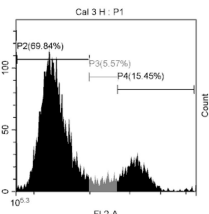

6

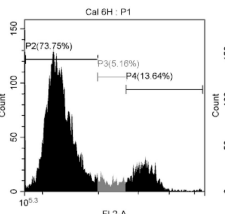

12

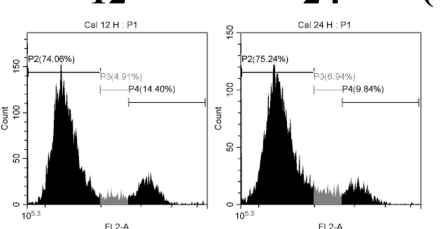

(h)

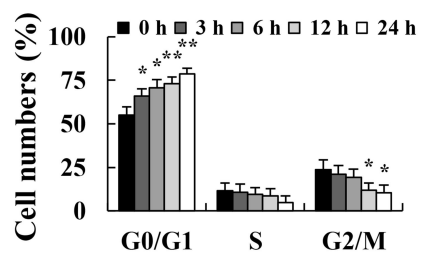

B
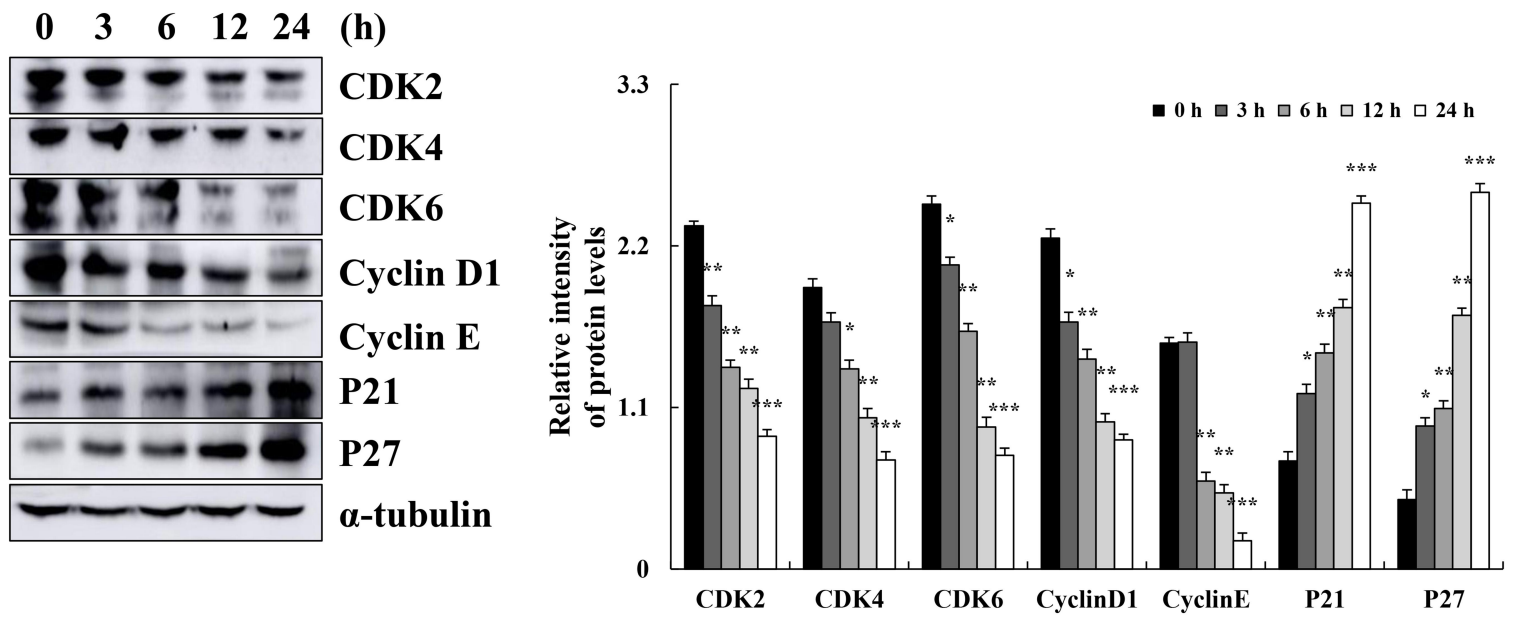

C

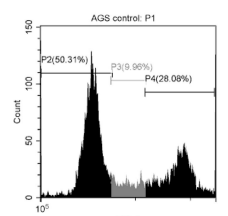

Calycosin

NAC

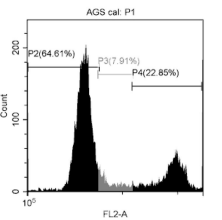

$+$

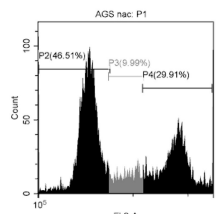

$-$

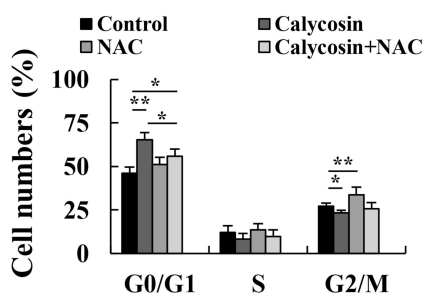

D

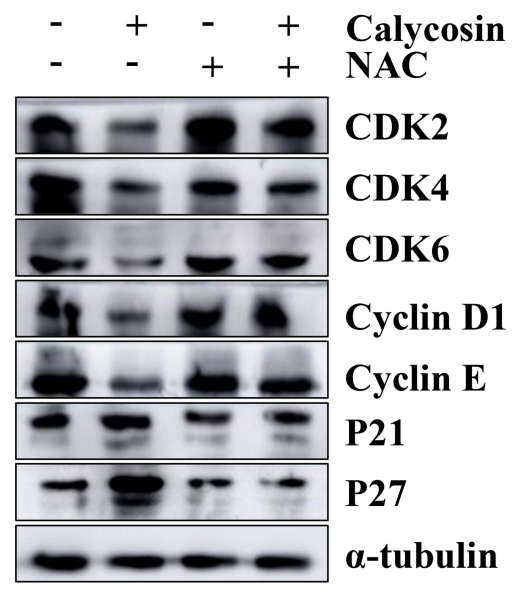

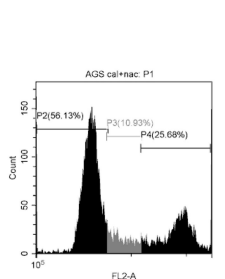

$+$

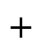

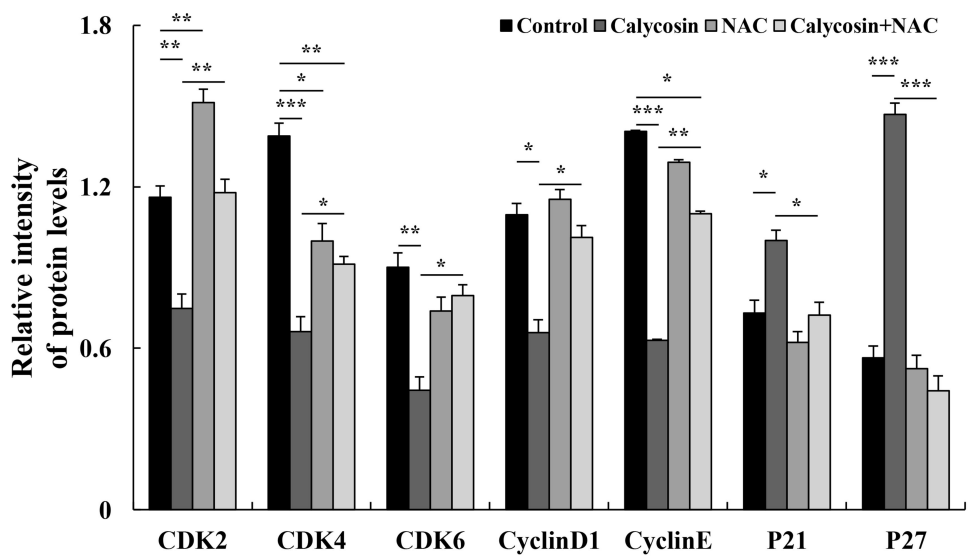

Figure 5 Effects of calycosin on the cell cycle and the expression of cell cycle-related proteins in AGS cells. (A) AGS cells were treated with $47 \mu \mathrm{M}$ calycosin for $0,3,6,12$, and $24 \mathrm{~h}$, and cell cycle distribution was analyzed by flow cytometry. (B) The expression levels of G0/GI cell cycle proteins CDK2, CDK4, CDK6, cyclin DI, cyclin E, p2I, and p27 were examined by Western blotting; $\alpha$-tubulin was used as the internal control. (C) The cell cycle of AGS cells was analyzed after pretreatment with NAC by flow cytometry. (D) The expression level of cell cycle was analyzed by Western blotting after pretreatment with NAC; $\alpha$-tubulin was used as the internal control. Representative data from at least three independent tests. ${ }^{*} \mathrm{p}<0.05$, ${ }^{*} \mathrm{p}<0.01$, and $* * * \mathrm{p}<0.001$. 


\section{Calycosin Inhibits Cells Migration Through ROS-Mediated Signaling Pathways in AGS Cells}

Calycosin inhibited AGS cell migration compared to the control group (Figure 6A). The expression levels of migration-associated proteins were detected by Western blotting, and calycosin significantly reduced the expression levels of SNAI 1, E-cadherin, and $\beta$-catenin (Figure 6B). Moreover, the inhibitory effect of calycosin was weakened after NAC was added (Figure 6C), and the levels of migration-associated proteins were increased after the addition of NAC (Figure 6D).

\section{Discussion}

TCM extracts inhibit cancer cell growth, proliferation, and differentiation, and thus have garnered great interest by researchers. ${ }^{19}$ However, TCMs often have a wide variety of characteristics and complex composition. The single components of Astragalus have been studied and showed that calycosin can inhibit the proliferation of osteosarcoma MG-63 cells and liver cancer BEL-7402 cells. ${ }^{20}$ Our study found that calycosin significantly inhibited the 12 types of GC cells (Figure 1A and C), with little to no cytotoxicity in the 4 normal cell lines (Figure 1B and D). To determine the potential mechanism of cytotoxicity, calycosin and AGS cells were used as research objects, studied in depth, and calycosin regulated ROS was found to induce AGS cells apoptosis.

Apoptosis plays an important role in cancer treatment, and the mitochondrial pathway is the main pathway of apoptosis. $^{21-23}$ A growing amount of evidence suggests that calycosin can potentially downregulate the antiapoptotic protein $\mathrm{Bcl}-2$; increase the expression levels of pro-apoptotic proteins cle-caspase-3, cle-PARP, and cytochrome $\mathrm{C}$; and induce human osteosarcoma by regulating the PI3K/AKT/mTOR signaling pathway. ${ }^{24,25}$ In this study, Hoechst 33342 and PI double staining showed that calycosin can promote cell apoptosis (Figure 2A). More importantly, compared with the control groups, calycosin increased early and late apoptosis in AGS cells (Figure 2B), and decreased the mitochondrial membrane potential (Figure 2C). Our results showed that calycosin promoted AGS apoptosis by upregulating the levels of Bad, clePARP, cle-caspase-3, and cytochrome $\mathrm{C}$ and downregulating Bcl-2 levels (Figure 2D). In addition, studies have shown that suppression of A549 cell proliferation and metastasis by calycosin via inhibition of the $\mathrm{PKC} \alpha /$
ERK1/2 pathway. $^{26-30}$ Our results indicated that the calycosin may regulate the MAPK/STAT3/NF- $\mathrm{B}$ pathway proteins binding to DNA or transcriptional activity, thereby promoting apoptosis in AGS cells (Figure 3A and B). To further investigate whether MAPK activation can regulate STAT3, MAPK inhibitors (FR180204, SP600125, and SB203580) were used to detect changes in STAT3 protein content. The results indicated that MAPK is located upstream of STAT3 (Figure 3C-E).

Oxidative stress and cellular redox imbalance will lead to excessive ROS, which promote apoptosis and necrosis under many physiological or pathological conditions. ${ }^{31,32}$ Previous studies have shown that ROS is a second messenger that mediates apoptosis by activating the MAPK cascade NF- $\kappa \mathrm{B}$ transcription factor. ${ }^{33}$ The phenolic hydroxyl groups at the $\mathrm{C}^{\prime}$ and $\mathrm{C}^{\prime}$ ' positions of the calycosin molecules are most likely to be active sites for the elimination of oxidative free radicals. In addition, calycosin has relatively small polarity, which not only removes oxidative free radicals but also penetrates the lipid bilayer to counteract lipid peroxidation. ${ }^{34}$ Our results indicated that the time to treat AGS cells with calycosin was positively correlated with the amount of ROS produced (Figure 4A). In addition, cell apoptosis (Figure 4B) and MAPK/STAT3/NF- $\kappa$ B (Figure $4 \mathrm{C}$ and D) were significantly reversed after NAC was added. These results showed that calycosin can upregulate ROS to promote cell apoptosis via MAPK/STAT3/NF-кB signaling pathway.

When cell proliferation is not restrained by a homeostatic mechanism, the tissue or organ can progress to cancer. $^{35-37}$ Calycosin may induce G0/G1 cell cycle arrest by promoting ROS production and regulating apoptosis-related signaling pathways. ${ }^{38}$ In this study, calycosin significantly reduced the levels of cyclin D1, cyclin E, CDK2, CDK4, and CDK6, and increased the expression levels of p27 and p21 in the arrested cell cycle at G0/G1 (Figure 5A and B). Similarly, calycosin inhibited cell migration (Figure 6A and B). Taken together, cell cycle (Figure 5C and D) and migration (Figure 6C and D) were significantly reversed after NAC pretreatment, which indicated that calycosin can upregulate ROS in cells arrested at the G0/G1 phase and inhibit cell migration.

Calycosin has anti-oxidation effects. ${ }^{39}$ Thus, we tested whether calycosin could specifically induce an increase in ROS in GC cells, but have antioxidant effects in normal cells (Supplementary Figure S1). Although we do not have clear proof that calycosin has a targeting effect on certain cell 
A o
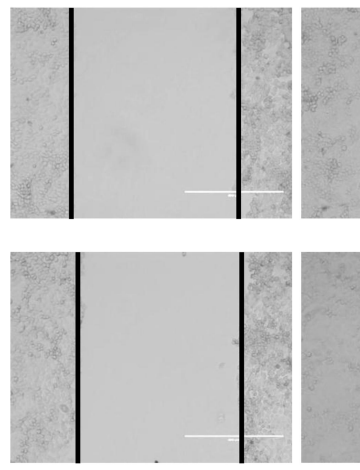

3
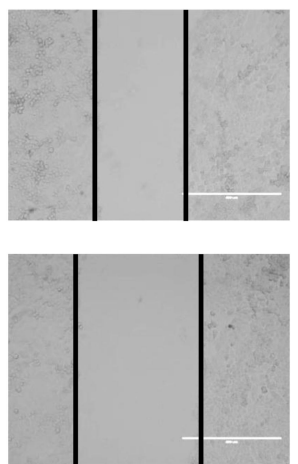

6
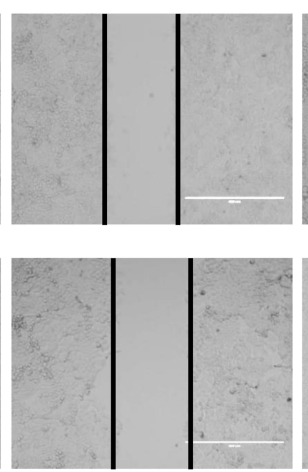

12
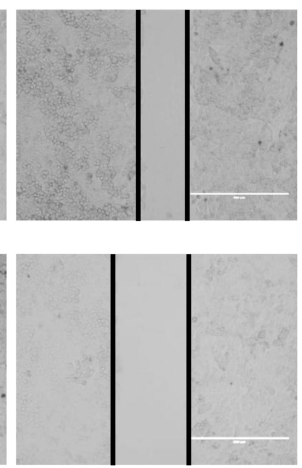

24
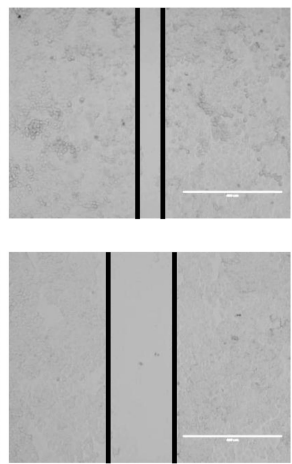

Control

(h)

\section{Calycosin}

B

$\begin{array}{llllll}0 & 3 & 6 & 12 & 24 & \text { (h) }\end{array}$
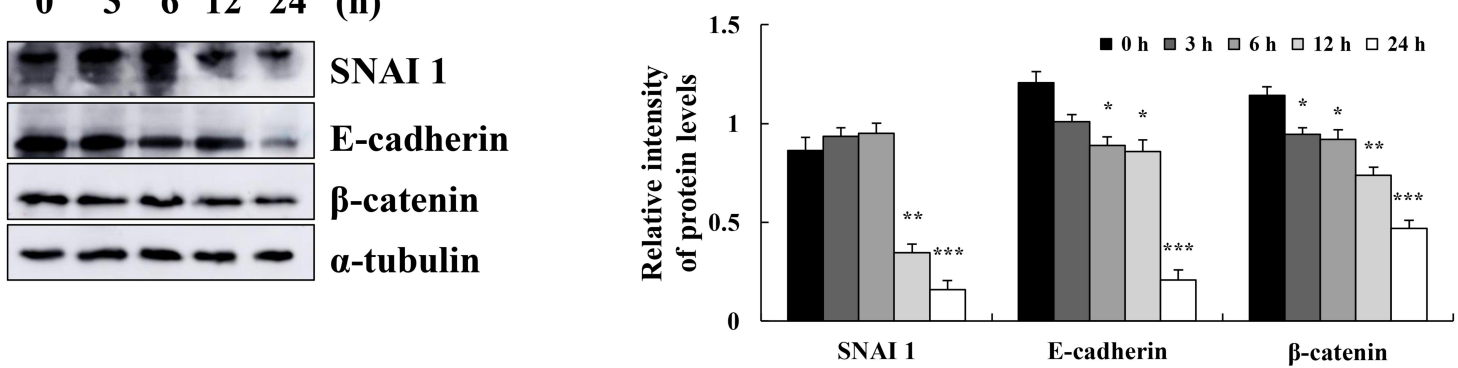

C
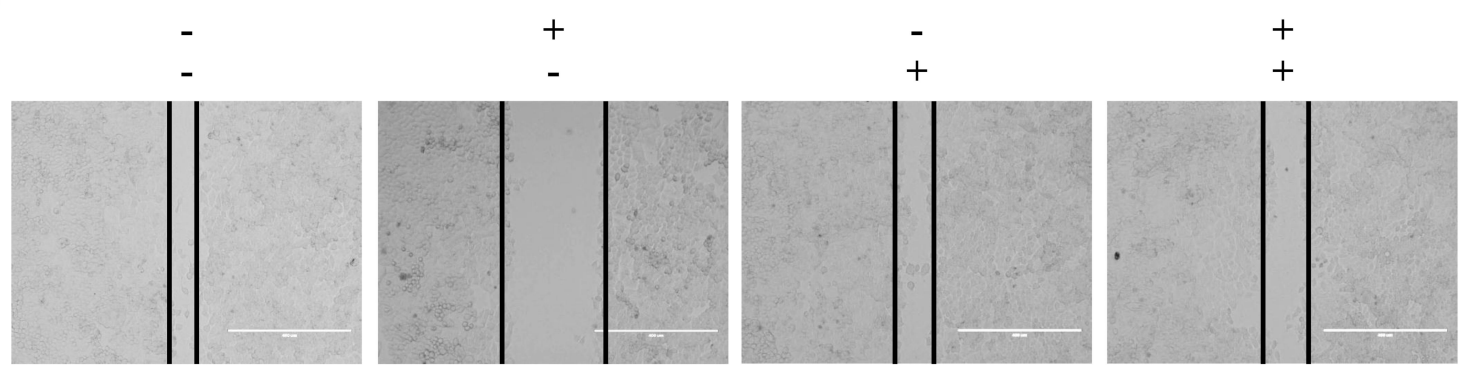

Calycosin NAC
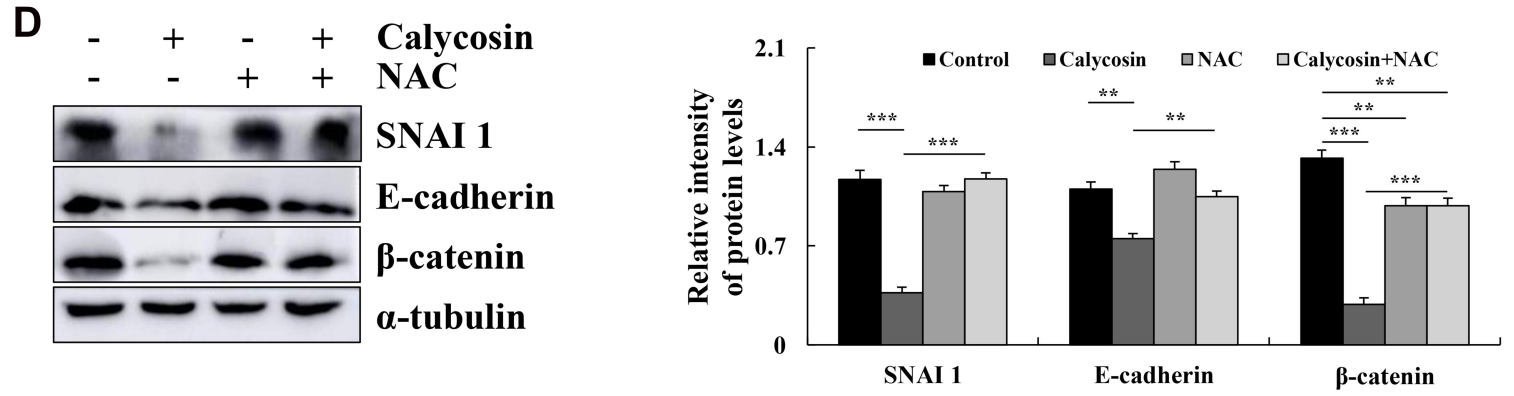

Figure 6 Effect of calycosin on the migration of AGS cells. (A) AGS cells were treated with calycosin ( $47 \mu \mathrm{M})$, and the images were taken under an inverted microscope. (B) Western blotting was used to analyze the expression of SNAI I, E-cadherin, and $\beta$-catenin. (C) AGS cells were pretreated with NAC, followed by the addition of calycosin $(47 \mu \mathrm{M})$ and imaging under an inverted microscope. (D) The expression of SNAI I, E-cadherin, and $\beta$-catenin was analyzed after pretreatment with NAC; $\alpha$-tubulin was used as the internal control. Representative data from at least three independent tests. ${ }^{*} p<0.05, *_{p}<0.01$, and $*^{* *} p<0.00 \mathrm{I}$.

membrane receptors, understanding the signal transduction relationships among profiles of calycosin can pave the way to progress on novel therapies with greater curative efficacy and fewer side effects. In addition, calycosin, a traditional Chinese medicine compound, the research and clinical application are still in its infancy. How calycosin binds to membrane surface receptors to enter cells, and by which ways it inhibits tumor cells proliferation and regulate immune activity needs to be further identified. Based on this, combined with relevant clinical practice theory, the 

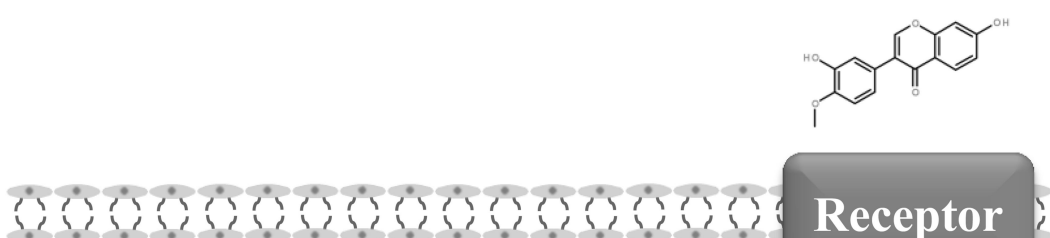

\section{Receptor}
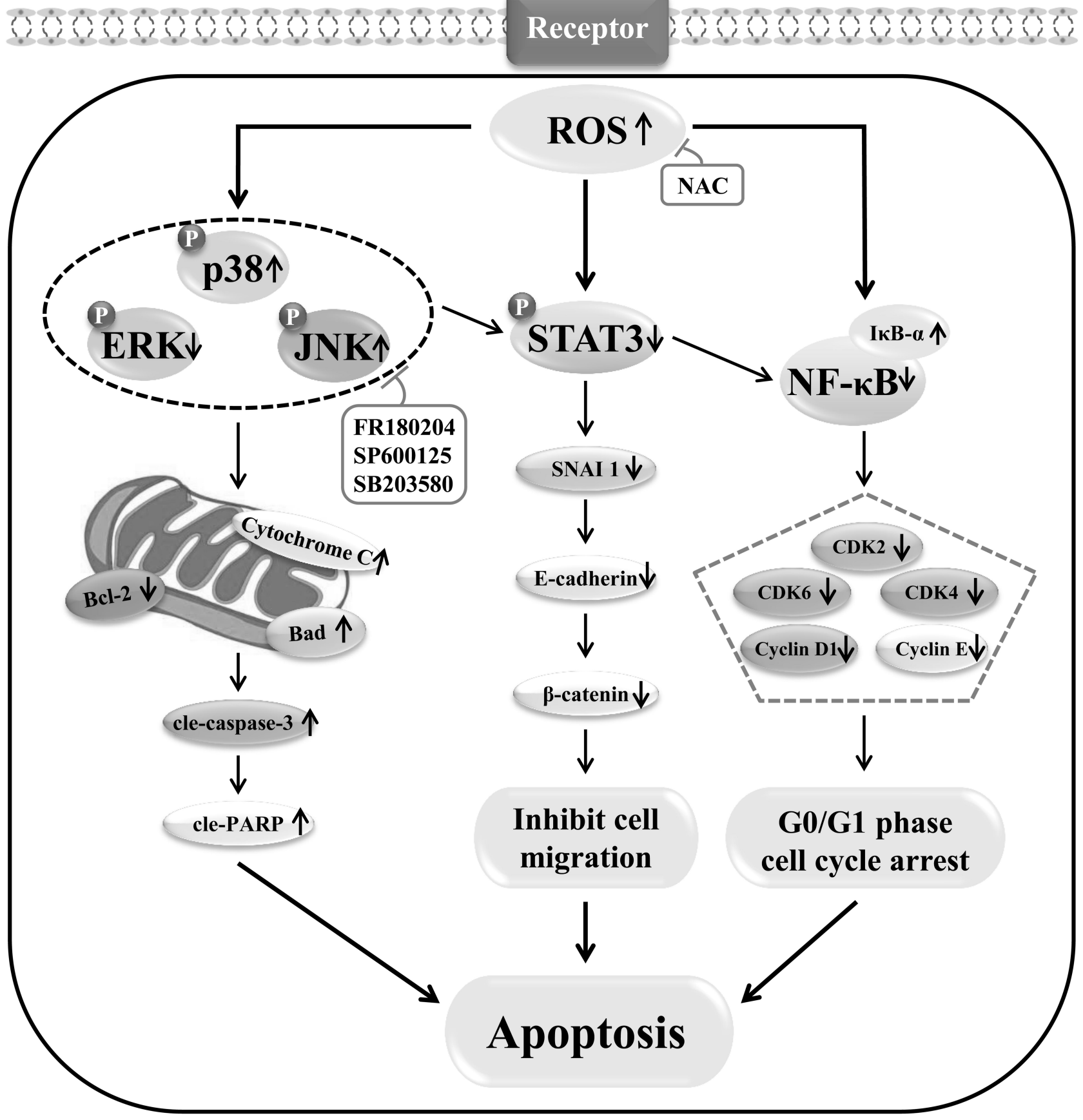

Figure 7 Schematic illustration of the underlying mechanism of calycosin effects on signaling pathways and the induction of apoptosis in GC cells.

calycosin is studied in depth from animal tumor model, various tumor cell models, and molecular level, is needed to promote the development of calycosin as a Chinese medicine target molecule for therapy tumors and lay a new cornerstone to improve the survival of life of cancer patients.

\section{Conclusion}

The molecular mechanism underlying the induction of apoptosis in AGS cells by calycosin includes increased levels of ROS and regulation of MAPK/STAT3/NF- $\mathrm{KB}$ signaling pathway-associated proteins, which leads to 
G0/G1 cell cycle arrest and inhibition of cell growth and migration (Figure 7). These results demonstrate that calycosin may be a potential target for the treatment of GC.

\section{Ethics Statement}

This article does not contain any studies with human or animal subjects.

\section{Acknowledgment}

We thank LetPub (www.letpub.com) for its linguistic assistance during the preparation of this manuscript.

\section{Funding}

This work was supported by the central government supports local college reform and development fund talent training projects, Heilongjiang Touyan Innovation Team Program (2019HTY078), the Project for Heilongjiang Bayi Agricultural University (XDB202012), the Heilongjiang Farms \& Land Reclamation Administration Support Project for Key Scientific Research (HKKYZD190705), the Heilongjiang Bayi Agricultural University Support Program for "San Zong" (TDJH201905), Heilongjiang Province College Student Innovation and Entrepreneurship Training Program Project (202010223001), and Heilongjiang Province College Student Innovation and Entrepreneurship Training Program Project (202010223004).

\section{Disclosure}

The authors declare they have no conflicts of interest for this work.

\section{References}

1. Wang F, Shen L, Li J, et al. The Chinese Society of Clinical Oncology (CSCO): clinical guidelines for the diagnosis and treatment of gastric cancer. Cancer Commun. 2019;39(1):10-41. doi:10.1186/s40880-0190349-9

2. McCall MD, Graham PJ, Bathe OF. Quality of life: a critical outcome for all surgical treatments of gastric cancer. World $J$ Gastroenterol. 2016;22(3):1101-1113. doi:10.3748/wjg.v22.i3.1101

3. Jian W, Jia Z, Jun L, et al. High tumor-associated macrophages infiltration is associated with poor prognosis and may contribute to the phenomenon of epithelial-mesenchymal transition in gastric cancer. Onco Targets Ther. 2016;9:3975-3983. doi:10.2147/OTT. S103112

4. Purohit V, Simeone DM, Lyssiotis CA. Metabolic regulation of redox balance in cancer. Cancers. 2019;11(7):955-979. doi:10.3390/ cancers 11070955

5. Huang M, Zhang L, Ding J, et al. Anticancer drug discovery from Chinese medicinal herbs. Chin Med. 2018;13(1):35-44. doi:10.1186/ s13020-018-0192-y
6. Yang H, Villani RM, Wang H, et al. The role of cellular reactive oxygen species in cancer chemotherapy. $J$ Exp Clin Cancer Res. 2018;37(1):266-276. doi:10.1186/s13046-018-0909-x

7. Jalmi SK, Sinha AK. ROS mediated MAPK signaling in abiotic and biotic stress-striking similarities and differences. Front Plant Sci. 2015;6:769-778. doi:10.3389/fpls.2015.00769

8. Keuss MJ, Hjerpe R, Hsia O, et al. Unanchored tri-NEDD8 inhibits PARP-1 to protect from oxidative stress-induced cell death. EMBO J. 2019;38(6):e100024. doi:10.15252/embj.2018100024

9. Huang Z, Liu CA, Cai PZ, et al. Omega-3PUFA attenuates MNU-induced colorectal cancer in rats by blocking PI3K/AKT/ BCL-2 signaling. Onco Targets Ther. 2020;13:1953-1965. doi:10.2147/OTT.S241298

10. Zhang XC. Effects of polydatin on the proliferation, migration, and invasion of ovarian cancer. BIOCELL. 2019;43(4):313-319. doi:10.32604/biocell.2019.07973

11. Alhoshani A, Alatawi FO, Al-Anazi FE, et al. BCL-2 inhibitor venetoclax induces autophagy-associated cell death, cell cycle arrest, and apoptosis in human breast cancer cells. Onco Targets Ther. 2020;13:13357-13370. doi:10.2147/OTT.S281519

12. Julien O, Wells JA. Caspases and their substrates. Cell Death Differ. 2017;24(8):1380-1389. doi:10.1038/cdd.2017.44

13. Liu Y, Xie X, Wang W, et al. A randomized controlled trial for the effect of Modified Shenling Baizhu Powder on delaying the illness progress of COPD stable phase patients (GOLD 1-2 stages): a study protocol. Medicine. 2020;99(43):e22700. doi:10.1097/ MD.0000000000022700

14. Lu Y, Yang J, Wang X, et al. Research progress in use of traditional Chinese medicine for treatment of spinal cord injury. Biomed Pharmacother. 2020;127:110136. doi:10.1016/j.biopha.2020.110136

15. Wu SY, Wang WJ, Dou JH, et al. Research progress on the protective effects of licorice-derived 18ß-glycyrrhetinic acid against liver injury. Acta Pharmacol Sin. 2020;42:18-26. doi:10.1038/s41401-020-0383-9

16. Jiang Y, Sun W, Li W, et al. Calycosin-7-O- $\beta$-D-glucoside promotes oxidative stress-induced cytoskeleton reorganization through integrin-linked kinase signaling pathway in vascular endothelial cells. BMC Complement Altern Med. 2015;15(1):315-326. doi:10.1186/ s12906-015-0839-5

17. Zhou R, Chen H, Chen J, et al. Extract from Astragalus membranaceus inhibit breast cancer cells proliferation via PI3K/AKT/mTOR signaling pathway. BMC Complement Altern Med. 2018;18(1):83-91. doi:10.1186/s12906-018-2148-2

18. Liu M, Li P, Zeng X, et al. Identification and pharmacokinetics of multiple potential bioactive constituents after oral administration of radix astragali on cyclophosphamide-Induced Immunosuppression in Balb/c Mice. Int J Mol Sci. 2015;16(3):5047-5071. doi:10.3390/ ijms 16035047

19. Chan SL, Ang X, Sani LL, et al. Prevalence and characteristics of adverse drug reactions at admission to hospital: a prospective observational study. $\mathrm{Br} J$ Clin Pharmacol. 2016;82(6):1636-1646. doi:10.1111/bcp.13081

20. Sun H, Yin M, Qian W, et al. Calycosin a PHYTOESTROGEN ISOfIAVONE INDUCES APOPTOSIS OF ESTROGEN RECEPTOR-POSITIve MG-63 Osteosarcoma Cells via the Phosphatidylinositol 3-Kinase (PI3K)/AKT/Mammalian Target of Rapamycin (mTOR) Pathway. Medical Science Monitor. 2018;24 (5):6178-6186. doi:10.12659/MSM.910201

21. Yang M, Liu B, Jin L, et al. Estrogen receptor $\beta$ exhibited anti-tumor effects on osteosarcoma cells by regulating integrin, IAP, NF-kB /BCL-2 and PI3K/Akt signal pathway. J Bone Oncol. 2017;9:15-20. doi:10.1016/j.jbo.2017.09.005

22. Nichani K, Li J, Suzuki M, et al. Evaluation of caspase-3 activity during apoptosis with fluorescence lifetime-based cytometry measurements and phasor analyses. Cytometry Part A. 2020;97 (12):1265-1275. doi:10.1002/cyto.a.24207 
23. Kamil A, Khan MA, Aasim M, et al. Detection of ROS and translocation of ERP-57 in apoptotic induced human neuroblastoma (SH-SY5Y) cells. BIOCELL. 2019;43(3):167-174.

24. Chertkova RV, Brazhe NA, Bryantseva TV, et al. New insight into the mechanism of mitochondrial Cytochrome $\mathrm{C}$ function. PLoS One. 2017;12(5):e0178280. doi:10.1371/journal.pone.0178280

25. Nie XH, Ouyang J, Xing Y, et al. Calycosin inhibits migration and invasion through modulation of transforming growth factor beta-mediated mesenchymal properties in U87 and U251 cells. Drug Des Devel Ther. 2016;10:767-779.

26. Wang Y, Xia CH, Lun ZQ, et al. Crosstalk between p38 MAPK and caspase-9 regulates mitochondria-mediated apoptosis induced by tetra- $\alpha$-(4-carboxyphenoxy) phthalocyanine zinc photodynamic therapy in LoVo cells. Oncol Rep. 2018;39:61-70. doi:10.3892/ or.2017.6071

27. Qin X, Yuan LQ, Ruan HX, et al. Interaction of IL-22/IL-22R1 promotes cell proliferation and suppresses apoptosis of colorectal cancer via phosphorylation of STAT3. BIOCELL. 2019;43(2):89-98.

28. Gilles C, Marie Odile F. The many roles of ubiquitin in NF- $\mathrm{B}$ signaling. Biomedicines. 2018;6(2):43-89. doi:10.3390/ biomedicines6020043

29. Ren M, Wang X, Du G, et al. Calycosin-7-O- $\beta$-d-glucoside attenuates ischemia-reperfusion injury in vivo via activation of the PI3K/Akt pathway. Mol Med Rep. 2016;13(1):633-640. doi:10.3892/ mmr.2015.4611

30. Cheng XD, Gu JF, Yuan JR, et al. Suppression of A549 cell proliferation and metastasis by Calycosin via inhibition of the PKC-/ ERK1/2 pathway: an in vitro investigation. Mol Med Rep. 2015;12 (6):7992-8002. doi:10.3892/mmr.2015.4449

31. Xia B, Wang J. Effects of adenosine on apoptosis of ovarian cancer A2780 cells via ROS and caspase pathways. Onco Targets Ther. 2019;12:9473-9480. doi:10.2147/OTT.S216620
32. Hiroyasu I, Tatsuya A, Mitsuru S. Inhibition of iNOS activity enhances the anti-tumor effects of alpha-galactosylceramide in established murine cancer model. Oncotarget. 2015;6(39):41863-41874. doi:10.18632/oncotarget.6172

33. Sergio DM, Tanea TR, Paola V. et al. Role of ROS and RNS Sources in Physiological and Pathological Conditions. Oxid Med Cell Longev;2016. 1245049-1245093. doi:10.1155/2016/1245049

34. Quan GH, Wang H, Cao J, et al. Calycosin Suppresses RANKLmediated osteoclastogenesis through inhibition of MAPKs and NFкB. Int J Mol Sci. 2015;16(12):29496-29507. doi:10.3390/ ijms161226179

35. Zerjatke T, Gak IA, Kirova D, et al. Quantitative cell cycle analysis based on an endogenous all-in-one reporter for cell tracking and classification. Cell Rep. 2017;19(9):1953-1966. doi:10.1016/j. celrep.2017.05.022

36. Xie Y, Li F, Li Z, et al. miR-135a suppresses migration of gastric cancer cells by targeting TRAF5-mediated NF- $\kappa$ B activation. Onco Targets Ther. 2019;12:975-984. doi:10.2147/OTT.S189976

37. Örd M, Venta R, Möll K, et al. Cyclin-specific docking mechanisms reveal the complexity of M-CDK function in the cell cycle. Mol Cell. 2019;75(1):76-89. doi:10.1016/j.molcel.2019.04.026

38. Guo C, Ma Y, Ma S, et al. The role of TRPC6 in the neuroprotection of calycosin against cerebral ischemic injury. Sci Rep. 2017;7 (1):3039-3052. doi:10.1038/s41598-017-03404-6

39. Liu C, Zheng P, Liu X, et al. Calycosin attenuates TNBS-induced colitis through inibiting inflammatory cytokine and oxidative stress. Int J Clin Exp Med. 2017;10(11):15094-15105.
OncoTargets and Therapy

\section{Publish your work in this journal}

OncoTargets and Therapy is an international, peer-reviewed, open access journal focusing on the pathological basis of all cancers, potential targets for therapy and treatment protocols employed to improve the management of cancer patients. The journal also focuses on the impact of management programs and new therapeutic agents and protocols on patient perspectives such as quality of life, adherence and satisfaction. The manuscript management system is completely online and includes a very quick and fair peer-review system, which is all easy to use. Visit http://www.dovepress.com/ testimonials.php to read real quotes from published authors 